Reviews in Digital Humanities • Vol. 3, No. 1

\title{
Review: Baltimore Traces
}

Brandon Walsh ${ }^{1}$

${ }^{1}$ University of Virginia

Published on: Jan 11, 2022

DOI: $10.21428 / 3 e 88 f 64 f .0 e 463 a 51$

License: Creative Commons Attribution 4.0 International License (CC-BY 4.0). 


\section{Project}

Baltimore Traces

Project Directors

Nicole King, University of Maryland, Baltimore County

Bill Shewbridge, University of Maryland, Baltimore County

Project URL

https://baltimoretraces.umbc.edu/

Project Reviewer

Brandon Walsh, University of Virginia

\section{Project Overview}

\section{Nicole King and Bill Shewbridge}

The Baltimore Traces: Communities in Transition project is a collaborative teaching initiative that brings students from a variety of disciplines in the arts and humanities together to create media focused on Baltimore neighborhoods. The foundational question of the project is, "How do neighborhoods change and how do people feel about those changes?" Working together to produce and share the engaging stories of city neighborhoods brings wider attention to issues such as deindustrialization, redevelopment, and gentrification while broadening student perspectives on their place in a broader community.

We named the project Baltimore Traces both to evoke the layers of change, traces upon the landscape, one can see and feel in historic cities like Baltimore, and to also evoke the poststructural idea of the "trace." For us, "traces" evoke remnants of the past that can mean different things to different people depending on their social location and historical context. Media can be used to document the past and the present as a way to connect these stories to the future of a more equitable city. The projects were designed to present perspectives and questions for the public to grapple with rather than offer solutions or answers.

Baltimore Traces evolved organically from years of collaboration between professors in the humanities with media producers, such as the founding director of our New Media Studio at the University of Maryland, Baltimore County (UMBC). Through our collaborations, we realized that working across departments and disciplines provides a 
more productive learning experience for students. The project began with funding from a 2015 Hrabowski Innovation Grant to bring students together to create podcasts for a local public radio partner but has expanded over time to include cultural documentation projects across the city working with various collaborators. The radio series received positive feedback from many quarters, including Phoebe Stein, Executive Director of Maryland Humanities at the time, who called the program, "An amazing, multi-faceted project. The best of public humanities and community engagement."

Students are trained in a team-based approach to field production, including video and audio recording, lighting, photography, and postproduction. Over the course of a semester, the production students collaborate with American studies students, who are trained in oral history and ethnographic interview methods and ethics, to create mediarich materials that are made publicly available on the project website. These include short video features, transcriptions, interactive maps, photo galleries, zines, and podcasts. The project has Institutional Review Board (IRB) approval and informed consent forms that are available for use in all associated courses. This project website is currently hosted through UMBC sites, which is a modified WordPress site.

The website serves as a community archive that makes student research as accessible as possible to the multiple publics it documents while also serving as a source for scholarly publications like Baltimore Revisited: Stories of Inequality and Resistance in a U.S. City (Rutgers University Press, 2019) and articles in the Journal of Urban History and the Journal of Higher Education Outreach and Engagement. Our approach to project assessment seeks to gauge students' perceptions and ownership of their knowledge acquisition as well as how it is practically applied in professional contexts beyond the classroom. The National Humanities Alliance's Humanities For All Project has highlighted Baltimore Traces for its connection of five core types of engagement in the publicly engaged humanities, including engaged teaching, engaged research, outreach through a variety of media, engaged public programming, and the "infrastructure of engagement."

\section{Project Review}

\section{Brandon Walsh}

Baltimore Traces represents years of work dedicated to elevating and sharing the stories of Baltimore's neighborhoods and their many associated communities. 
Overseen by Nicole King and Bill Shewbridge, both faculty members at the University of Maryland, Baltimore County, the project is a collection of teaching initiatives and the resulting multimedia projects produced by students over the years. Baltimore Traces challenges narratives about the city by elevating community members' own stories while resituating students as more than just temporary inhabitants of their cities. As the "About" page notes, the project aims to draw critical attention to "deindustrailization [sic], redevelopment, and gentrification while broadening student perspectives on their place in a broader community." The project shows the power of student voices to contribute to public humanities work at a time of special political urgency by demonstrating that teaching and learning can engage students as contributors to-and participants in-their communities. In this way, the project follows in the tradition of public humanities projects like Our Marathon by practicing a digital humanities that is critically engaged, local, and very much co-created with its community.

Baltimore Traces shows how powerful cross-institutional collaborations can be for developing unique student experiences. The project was a collaboration between faculty members, the Center for Emerging Media (a Baltimore non-profit), and participants from the surrounding communities. The student projects span an impressive range of media formats: photographs, Knight Lab StoryMaps, video interviews, zines, podcasts, and audio recordings of radio programming. This array of student work is remarkable both for the final products as much as for the pedagogical labor that guided the production of such a robust and varied set of materials. Other instructors might benefit from further foregrounding of this teaching process: the student work is rich and varied, and it makes one want to see the syllabi and instructional materials that helped produce them.

The 2014 series, entitled "Stories of Deindustrialized Baltimore,". uses the narratives of community members to craft a story of the effects of industrialization on the pasts, presents, and futures of Baybrook and the Sparrows Point Steel Mill. Created when faculty collaborated with a local radio partner to have students develop a series of podcasts on local communities, students aimed to share the oral histories of these industrial places by the residents and neighbors who knew them best. This approach typifies the approach to and quality of the work found across the range of student projects on display in Baltimore Traces.

Baltimore Traces itself is housed on UMBC Sites, a modified WordPress setup developed by the institution's Department of Information Technology. One of the 
challenges of such a multifaceted and rich project like this is the technical stack involved. In addition to hosting its own materials, the site also depends on embedded or linked content from Flickr, YouTube, and SoundCloud. Students might already be familiar with platforms like these, which can make them easier to integrate in the classroom than other more sustainable options. But this ease of use might bring it with a tradeoff, potentially making the outcomes vulnerable to disappearing in the future.

Baltimore Traces is not alone in depending on platforms and companies like these to carry out digital work. However, this project makes a significant contribution to Baltimore precisely because it makes something local and vital legible for a broader audience. As a field, we need to reckon more clearly with how to make contributions like these durable as well, safe from changes in technology or corporate leadership that might erase them in the future. Despite these challenges, Baltimore Traces presents an exciting way forward for digital humanities teaching to which we can all aspire, and the work on display here deserves to be shared for years to come. 